\title{
Polymethylmethacrylate Incorporating Nanodiamonds for Denture Repair: In Vitro Study on the Mechanical Properties
}

\author{
Mohammed M. Gad ${ }^{1}$ Mohamed Saber Ali ${ }^{1} \quad$ Ahmad M. Al-Thobity ${ }^{1}$ Yousif A. Al-Dulaijan ${ }^{1}$ \\ Mai El Zayat ${ }^{1} \quad$ Abdel-Naser M. Emam ${ }^{2}$ Sultan Akhtar ${ }^{3}$ Soban Q. Khan ${ }^{1}$ Fahad A. Al-Harbi ${ }^{1}$ \\ Shaimaa M. Fouda ${ }^{1}$
}

1 Department of Substitutive Dental Sciences, College of Dentistry, Imam Abdulrahman Bin Faisal University, Dammam, Saudi Arabia

2 Department of Removable Prosthodontics, Faculty of Dental

Medicine (Boys), Al-Azhar University, Cairo, Egypt

${ }^{3}$ Department of Biophysics, Institute for Research and Medical

Consultations, Imam Abdulrahman Bin Faisal University, Dammam, Saudi Arabia

Eur J Dent 2022;16:286-295.
Address for correspondence Mohammed M. Gad, BDS, MSc, Department of Substitutive Dental Sciences, College of Dentistry, Imam Abdulrahman Bin Faisal University, P.O. Box 1982, Dammam 31441, Saudi Arabia (e-mail: mmjad@iau.edu.sa).

\begin{abstract}
Keywords

- nanoparticles

- polymethylmethacrylate

- reinforcement

- repair gap

- repair strength
\end{abstract}

Objective This study aimed to evaluate the effect of nanodiamond (ND) addition to repair resin with repair gap modifications on the flexural and impact strength of repaired polymethylmethacrylate denture base.

Materials and Methods Heat-polymerized acrylic resin specimens ( $N=100 /$ test) were prepared and sectioned to half creating two repair gaps: $2.5-$ and $0 \mathrm{~mm}$ with 45 degrees beveling. They were further divided into subgroups $(n=20)$ according to ND concentration (control, $0.25 \% \mathrm{ND}$, and $0.50 \% \mathrm{ND}$ ), thermocycling (500 cycles) was done to half the specimens in each subgroup. Flexural strength was tested using 3point bending test and impact strength was tested by Charpy's impact test. Analysis of variance and post-hoc Tukey's tests were performed for data analysis $(\alpha=0.05)$. Scanning electron microscope was employed for fracture surface analysis and ND distribution.

Results Before and after thermocycling, the addition of ND significantly increased the flexural strength and elastic modulus in comparison to control group $(p<0.001)$, while $0 \mathrm{~mm}$ repair gap showed insignificant difference between ND-reinforced groups ( $p>$ 0.05). Regarding impact strength, ND addition increased the impact strength with $0 \mathrm{~mm}$ gap in comparison to control and $2.5 \mathrm{~mm}$ with ND $(p<0.001)$, while later groups showed no significant in between $(p>0.05)$. Comparing thermocycling effect per respective concentration and repair gap, thermocycling adversely affected all tested properties except elastic modulus with $0 \mathrm{~mm}-0.25$ and $0 \mathrm{~mm}-0.5 \%$ and impact strength with $2.5 \mathrm{~mm}, 2.5 \mathrm{~mm}-0.25 \%, 2.5 \mathrm{~mm}-0.5 \%$ ( $p>0.05)$.

Conclusion ND addition combined with decreased repair gap improved the flexural strength, elastic modulus, and impact strength of repaired denture resin, while thermocycling has a negative effect on denture repair strength. published online

November 25, 2021
DOI https://doi.org/

10.1055/s-0041-1735792. ISSN 1305-7456.

\section{(c) 2021. The Author(s).}

This is an open access article published by Thieme under the terms of the Creative Commons Attribution License, permitting unrestricted use, distribution, and reproduction so long as the original work is properly cited. (https://creativecommons.org/licenses/by/4.0/)

Thieme Medical and Scientific Publishers Pvt. Ltd., A-12, 2nd Floor, Sector 2, Noida-201301 UP, India 


\section{Introduction}

Denture fracture commonly occurs due to the low impact and flexural strength of denture base resin. Sudden drop of the denture is the most common cause of dentures fracture. Denture repair is frequent in dental practice; it requires less expenses and time than fabrication of a new denture. ${ }^{1,2}$ The material used for denture repair should attain the original denture color and strength as well as dimensional stability. ${ }^{3}$ Autopolymerized acrylic resin is the most commonly used material for denture repair because of its good color match and ease of manipulation that allows chairside repair. ${ }^{4}$ However, it has poor strength that ranges between 18 and $81 \%$ of heat polymerized acrylic resin. ${ }^{4}$ Success of denture repair is affected by the type and/or reinforcement of repair resin, in addition to repair surface treatment and design., 2,5

Denture repair begins with preparing a repair gap to provide space for repair material. ${ }^{2}$ The extent of repair gap defines the quantity of added repair material thus affecting the strength of denture repair. ${ }^{2,5}$ Several previous studies have tested the size of repair gap, which ranged between 1 and $10 \mathrm{~mm} \cdot{ }^{5-8}$ However, limited studies have tested the influence of repair gap size on strength of repaired denture, while most studies have investigated repair design, surface treatment, and reinforcement of repair material. ${ }^{2} \mathrm{~A}$ repair gap of $3 \mathrm{~mm}$ or less is preferred due to less repair material used and consequently less polymerization shrinkage and color variation between the denture base and repair resin., ${ }^{6,7}$ With decreasing the repair gap from 3 to $1.5 \mathrm{~mm}$, the deflection was decreased by $20 \%{ }^{8}$ Gad et al ${ }^{5}$ suggested decreasing repair gap even up to $0 \mathrm{~mm}$ repair gap and reported an increase in flexural strength as repair gap decreased, while impact strength increased with 2 and $1.5 \mathrm{~mm}$ repair gaps. On the other hand, larger repair gaps were affected by thermal cycling. Therefore, decreasing repair gap was recommended as an approach to improve repair strength. ${ }^{5}$

Hanna et $\mathrm{al}^{9}$ reported that 45 degrees bevel repair surface design improved repair strength. Moreover, repair surface treatment with monomer alters the surface structure and improves the bond at repair/resin interface. ${ }^{9,10}$ Repair surface beveling with monomer application showed cohesive failure within the repair resin instead of adhesive failure. ${ }^{2,9,10}$ The cohesive fracture type of repair resin confirmed the responsibility of repair resin for weak repair strength. ${ }^{2}$ Therefore, repair resin reinforcement was suggested using wires, fibers, ${ }^{2}$ filler, or nanofillers. ${ }^{10,11}$ Nanofillers are widely used due to their inherent properties such as nanoscale with big particular surface area and interfacial interactivity with organic polymers. ${ }^{12}$ The main purpose of nanoparticles incorporation into dental polymeric materials was to improve some of the mechanical properties of the final nanocomposites. ${ }^{12,13}$

Several nanoparticles were used to improve denture repair material including $\mathrm{ZrO}_{2}, \mathrm{Al}_{2} \mathrm{O}_{3}$, and $\mathrm{SiO}_{2}$ nanoparticles. ${ }^{10,11,14-16} \mathrm{ZrO}_{2}$ nanoparticles addition improved the transverse strength and impact strength of repair resin. ${ }^{10,11,16} \mathrm{SiO}_{2}$ nanoparticles with 45 degrees beveled repair surface increased flexural strength of repaired acrylic resin. ${ }^{14} \mathrm{Al}_{2} \mathrm{O}_{3}$ nanoparticles improved the flexural strength of repair resin compared with the unmodified resin. ${ }^{16}$ Nanodiamond (ND) belongs to nanocarbon family and possesses distinctive properties permitting its use for dental applications. ${ }^{17-19}$ ND has been tested in previous studies as filler to heat polymerized denture base resin. Al-Harbi et al ${ }^{18}$ concluded that the impact strength of polymethylmethacrylate (PMMA) was lowered as ND increased and recommended the addition of ND in low concentrations. Similarly, Protopapa et $\mathrm{al}^{20}$ reported an improvement in the mechanical properties of provisional restorations fabricated from autopolymerized PMMA resin reinforced with low ND concentrations. Furthermore, addition of ND to PMMA reduced Candida albicans adhesion. ${ }^{19}$

Although ND showed a positive effect on the properties of PMMA/ND composite, its effect on denture repair base material along with $0 \mathrm{~mm}$ repair gap has not been investigated previously. Therefore, the aim of the present study was to determine the influence of low ND concentrations on strength of denture repair resin. The first null hypothesis was that the repair gap variations would not affect the flexural properties and impact strength of autopolymerized repair resin. The second null hypothesis was that addition of ND to autopolymerized repair resin would not affect its flexural and impact strength.

\section{Materials and Methods}

Sample size calculations revealed that 200 specimens (100 per test $/ n=10$ ) were required to conduct this study. Acrylic resin specimens were prepared following ISO standard 1567:1999/Amd.1:2003(E). ${ }^{21}$ For flexural properties, acrylic plates were prepared in dimensions $65 \times 10 \times 2.5 \mathrm{~mm}$, while for impact strength specimens were prepared in dimension of $50 \mathrm{~mm}$ lengths $\times 6 \mathrm{~mm}$ width $\times 4 \mathrm{~mm}$ thickness. At the middle of impact strength specimen, a standard v-notch was prepared with depth $0.8 \mathrm{~mm}$ through the whole $6 \mathrm{~mm}$ width of the specimen leaving $3.2 \mathrm{~mm}$ thickness below the notch. ${ }^{21} \mathrm{~A}$ customized split press metal mold with required dimensions was used for wax specimens' preparations. Heat polymerized PMAA acrylic resin (Major base 20; Major Prodotti Dentari SPA, Italy) was used to fabricate all specimens following the conventional method for denture base fabrication as described in previous studies. ${ }^{5,18}$ A digital caliper was used to evaluate specimens dimension and specimens with improper dimensions were excluded. Approved specimens were kept in distilled water for 2 days at $37^{\circ} \mathrm{C}$.

Specimens' preparation for repair was performed according to the method described in a previous study. ${ }^{5}$ For the $2.5 \mathrm{~mm}$ group, a diamond disc (REF 5990 3107, DeguDent $\mathrm{GmbH}$, Wolfgang, Germany) was used to section the specimens creating a repair gap of $2.5 \mathrm{~mm}$ and $45^{\circ}$-beveled repair surface. For $0 \mathrm{~mm}$ group, the specimens were sectioned into equal halves with $45^{\circ}$ bevel at the cameo surface of the inner ends of the two sections preserving the normal length of specimens at on the intaglio side ( $\mathbf{F i g . ~} \mathbf{1}) .^{10}$ 


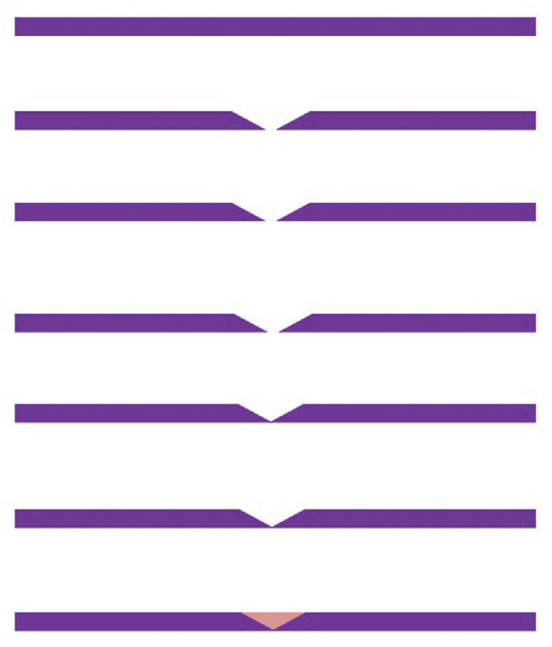

Intact

2.5mm- 0\%ND

$2.5 \mathrm{~mm}-0.25 \% \mathrm{ND}$

$2.5 \mathrm{~mm}-0.50 \% \mathrm{ND}$

Omm- $0.25 \% \mathrm{ND}$
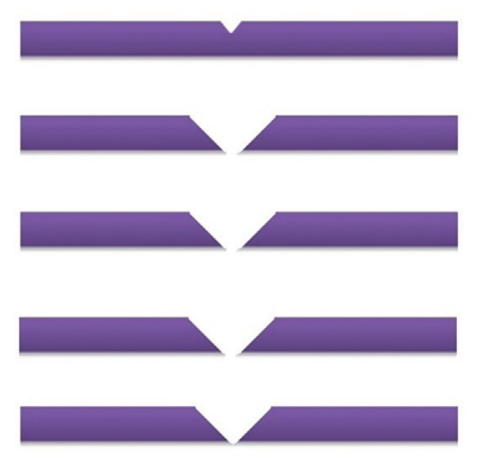

Omm- $0.50 \%$ ND

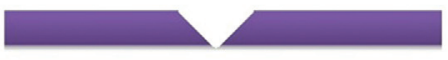

Omm - repaired

Fig. 1 Schematic diagram for acrylic resin specimens preparation and repair. ND, nanodiamond.

ND (Shanghai Richem International Co. Ltd, Shanghai, China) with purity: 98-99\%, and particle size: 30-40 nm was treated as described in previous studies. ${ }^{18,19}$ Digital scale (S-234, Denver Instrument) was used to weight the treated ND particles in concentrations of 0.25 and $0.50 \%$, by weight of autopolymerized repair PMMA resin powder (Major repair; Prodotti Dentari SPA, Italy). According to ND concentrations and repair gap size, specimens were randomly distributed to five groups: control, without ND addition and 4 tested groups with $0.25 \% \mathrm{ND}, 0.50 \% \mathrm{ND}$ ( - Table 1 ). All mixtures separately were initially mixed with hand and then stirred using electric mixer for 30 minutes at $400 \mathrm{rpm}$ to ensure homogenous distributions of nanoparticles within resin powder. $^{18}$

Treatment of repair surface was done by monomer application for 180 second and then the 2 halves of the specimen were reassembled in the original metal molds. The repair resin was mixed and packed following the manufacturer instructions, overfilling the repair gap, then placed in pot pressure with $45^{\circ} \mathrm{C}$. After complete polymerization, specimens were removed from the mold. The excess resin was removed using the conventional finishing and polishing techniques for denture base. Then, specimens' dimensions were reevaluated with the digital caliper and kept in distilled water for 72 hours at $37^{\circ} \mathrm{C}$ prior testing.

The three-point bending test was performed using a universal testing machine (Instron, 5965, United States). A custom-made stainless steel device that included a $50 \mathrm{~mm}$ span between the two supports was employed. Using a $2 \mathrm{~mm}$ blunt round end tip, a load with $5 \mathrm{~mm} / \mathrm{min}$ crosshead speed was performed centrally to the intaglio surface of the specimens at the repaired area. Recording of the maximum load at fracture was performed, and the flexural strength (FS) and elastic modulus were calculated as described in previous studies. $^{5,21}$

Charpy's impact testing machine (Digital Charpy Izod impact tester, XJU 5.5, Jinan Hensgrand Instrument Co., Ltd., Jinan, China) was used to measure the impact strength. After horizontal placement of the specimen on a metal jig with $40 \mathrm{~mm}$ distance between two supports, a pendulum with $0.5 \mathrm{~J}$ weight was fallen at the back side of the specimens (opposite to the notch). The absorbed energy required for

Table 1 Specimens grouping and coding according to repair gap, nanodiamond (ND) concentrations, and thermocycling

\begin{tabular}{|c|c|c|c|}
\hline Thermocycling & Gap & Code & Specifications \\
\hline \multirow[t]{5}{*}{0 cycle } & \multirow[t]{3}{*}{$2.5 \mathrm{~mm}$} & $2.5 \mathrm{~mm}$ & Repaired with unmodified repair resin \\
\hline & & $2.5 \mathrm{~mm}-0.25 \% \mathrm{ND}$ & Repaired with repair resin reinforced with $0.25 \%$ ND \\
\hline & & $2.5 \mathrm{~mm}-0.50 \% \mathrm{ND}$ & Repaired with repair resin reinforced with $0.50 \%$ ND \\
\hline & \multirow[t]{2}{*}{$0 \mathrm{~mm}$} & $0 \mathrm{~mm}-0.25 \% \mathrm{ND}$ & Repaired with repair resin reinforced with $0.25 \%$ ND \\
\hline & & $0 \mathrm{~mm}-0.50 \% \mathrm{ND}$ & Repaired with repair resin reinforced with $0.50 \%$ ND \\
\hline \multirow[t]{5}{*}{5.000 cycles } & \multirow[t]{3}{*}{$2.5 \mathrm{~mm}$} & $2.5 \mathrm{~mm}$ & Repaired with unmodified repair resin \\
\hline & & $2.5 \mathrm{~mm}-0.25 \% \mathrm{ND}$ & Repaired with repair resin reinforced with $0.25 \%$ ND \\
\hline & & $2.5 \mathrm{~mm}-0.50 \% \mathrm{ND}$ & Repaired with repair resin reinforced with $0.50 \%$ ND \\
\hline & \multirow[t]{2}{*}{$0 \mathrm{~mm}$} & $0 \mathrm{~mm}-0.25 \% \mathrm{ND}$ & Repaired with repair resin reinforced with $0.25 \%$ ND \\
\hline & & $0 \mathrm{~mm}-0.50 \% \mathrm{ND}$ & Repaired with repair resin reinforced with $0.50 \%$ ND \\
\hline
\end{tabular}




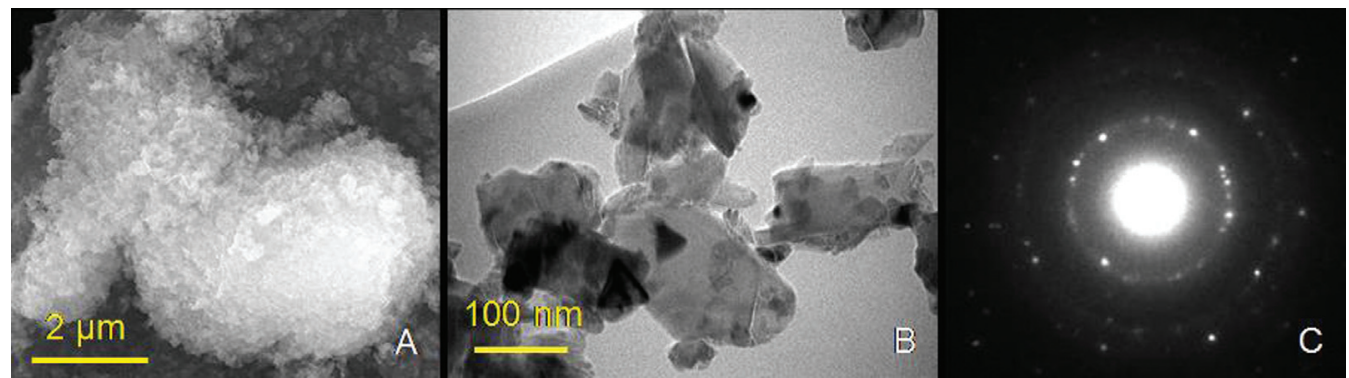

Fig. 2 (A) Scanning electron microscopy micrograph of nanodiamond (ND) powder, (B) transmission electron microscopy image of ND powder, and $(C)$ corresponding selected area electron diffraction (SAED) pattern for crystalline material.
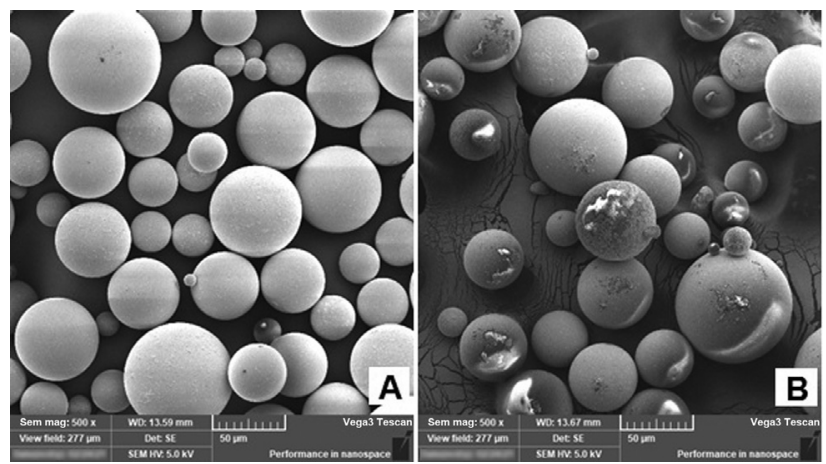

Fig. 3 Scanning electron microscopy micrographs of (A) pure polymethylmethacrylate and (B) polymethylmethacrylate/nanodiamond mixture.

specimen fracture was digitally displayed on the monitor and recorded impact strength value $\left(\mathrm{kJ} / \mathrm{m}^{2}\right)$. The data were collected and tabulated for statistical analysis.

After testing, the FS specimens were coated with gold and analyzed under scanning electron microscopy (SEM; TESCAN Vega3 with working voltage of $20 \mathrm{kV}$ ) as described in previous studies. ${ }^{18,24}$ The electron micrographs were recorded at different magnifications, namely x200, x500 and $x 1000$ to reveal the maximum features of the fractured surfaces. To reveal the size, shape, and structure of the individual particles of the nano-diamond (ND), the ND powder (ND dispersion) was deposited onto SEM holder (TEM grid) and examined under SEM and transmission electron microscope (TEM, Morgagni 268, FEI, with working voltage of $80 \mathrm{kV}$ ) for high resolution (-Fig. $2 \mathbf{A}$ and $\mathbf{B}$ ). The crystalline structure of the ND nano-powder was verified by electron diffraction performed in the TEM (-Fig. 2C). The shape of the ND particles was irregular with thickness of few tens of nanometers. Furthermore, the prepared PMMA/ND mixture was also examined under SEM to realize the distribution and existence of the ND particles within PMMA powder before going to use heat polymerization treatment (-Fig. 3).

Statistical package for social sciences (SPSS v. 23) was used to enter and analyzed data. In descriptive statistics, mean and standard deviations were computed. For inferential statistics, normality of the data was tested first by using Shapiro-Wilk test and insignificant results were provided that data was normally distributed; hence, parametric tests were used for analysis. One-way analysis of variance (ANOVA) was used to study the variation in tested properties with different levels of repair gap and with different level of ND concentrations followed by post-hoc Tukey's test for pairwise comparison. Two-way ANOVA was used to study the combined effect of repair gap and thermocycling effect (before and after) on properties. Two independent samples $t$-test was performed to test the significance in difference in averages before and after thermocycling effect for each tested property. Chisquared test was performed to study the association between thermocycling effect (before and after) and nature of failure. Level of significance was set as 0.05 .

\section{Results}

One-way ANOVA was performed to test the effect of variation in repair gap with concentration over the tested properties and it was analyzed separately before and after thermocycling (-Table 2). Flexural strength, elastic modulus, and impact strength showed statistically significant differences (-Table 2). Flexural strength mean values before thermocycling were significantly higher than that after thermocycling among all the groups $(p<0.05$; ( - Table 3 ). The lowest mean value of flexural strength was reported at control group $(2.5 \mathrm{~mm})$, while the highest value was recorded with $0.25 \%$ ND for both repair gaps ( 2.5 and $0 \mathrm{~mm}$ ) before and after thermocycling. Between ND-reinforced groups, insignificant differences were found before thermocycling between $2.5 \mathrm{~mm}-0.25 \%$ versus $0 \mathrm{~mm}-0.25 \%(p=0.505)$ and $2.5 \mathrm{~mm}--$ $0.5 \%$ versus $0 \mathrm{~mm}-0.5 \%$ ( $p=0.664)$, while for the rest of the pairs, difference was statistically significant. After thermocycling, differences between ND groups were found statistically insignificant in pairs $2.5 \mathrm{~mm}-0.25 \%$ versus $0 \mathrm{~mm}-0.25 \%$ $(p=0.401), 2.5 \mathrm{~mm}-0.5 \%$ versus $0 \mathrm{~mm}-0.5 \%(p=0.305)$ and $0 \mathrm{~mm}-0.25 \%$ versus $0 \mathrm{~mm}-0.5 \%(p=0.211)$.

Regarding the elastic modulus, lowest mean was found at $2.5 \mathrm{~mm}$ (control) before and after thermocycling. While the highest average was noticed at $2.5 \mathrm{~mm}-0.5 \%$ before thermocycling and at $0 \mathrm{~mm}-0.25 \%$ after thermocycling, the elastic modulus of ND-reinforced groups was significantly increased when compared with control group $(p<0.001)$ before and after thermocycling except control versus $2.5 \mathrm{~mm}-0.25 \%$ before thermocycling $(p=0.202)$. In between ND-reinforced groups without thermocycling effect, all pairs had statistically insignificant differences. While after 

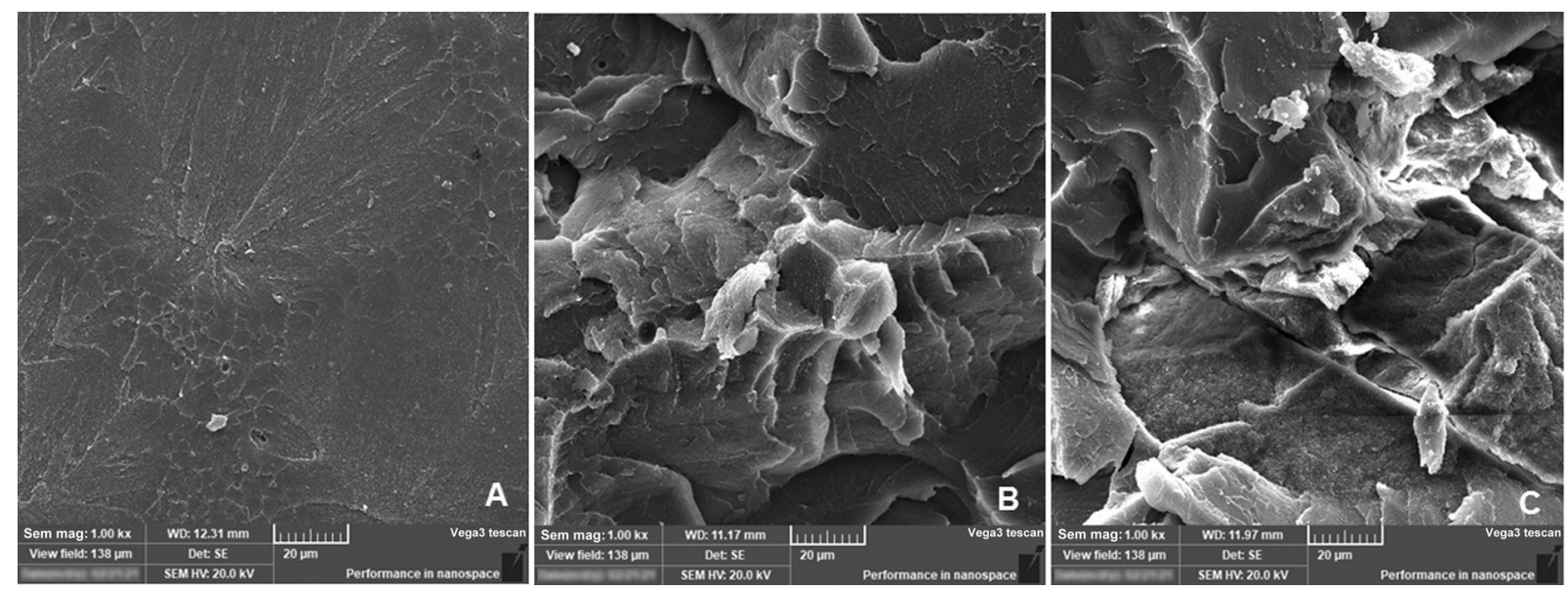

Fig. 4 Representative scanning electron microscopy images for fracture surface of flexural strength test specimens $2.5 \mathrm{~mm}$ groups after thermocycling. (A) $2.5 \mathrm{~mm}-0 \% \mathrm{ND}$, (B) $2.5 \mathrm{~mm}-0.25 \% \mathrm{ND}$, and (C) $2.5 \mathrm{~mm}-0.5 \% \mathrm{ND}$.

thermocycling, the only pair that had significant difference was $2.5 \mathrm{~mm}-0.25 \%$ versus $0 \mathrm{~mm}-0.25 \%(p=0.002)$. Within the groups, elastic modulus values were reduced significantly after thermocycling except $0 \mathrm{~mm}-0.25 \%(p=0.176)$ and $0 \mathrm{~mm}-0.5 \%(p=0.094 ;$ - Table 3$)$.

The lowest impact strength values were found at $2.5 \mathrm{~mm}-0.25 \%$ before and after thermocycling. While the highest values were noticed at $0 \mathrm{~mm}-0.5 \%$ before thermocycling and at $0 \mathrm{~mm}-0.25 \%$ after thermocycling, ND-reinforced groups, $0 \mathrm{~mm}-0.25 \%$ and $0 \mathrm{~mm}-0.5 \%$, showed significant increase in impact strength when compared with control group with $p=0.001$ and $p<0.001$, respectively, before thermocycling. However, comparison between control and ND-reinforced group after thermocycling, statistically significant differences were found between control versus $0 \mathrm{~mm}-0.25 \%(p=0.000)$ and control versus $2.5 \mathrm{~mm}-$ $0.5 \%(p=0.002)$. In between ND-reinforced groups, before thermocycling effect, insignificant differences were found at $2.5 \mathrm{~mm}-0.25 \%$ versus $2.5 \mathrm{~mm}-0.5 \%(p=0.105), 0 \mathrm{~mm}-0.25 \%$ versus $0 \mathrm{~mm}-0.5 \%(p=0.595)$. However, after thermocycling, significant differences were found at $2.5 \mathrm{~mm}-0.25 \%$ versus $0 \mathrm{~mm}-0.25 \%$ with $p<0.001,2.5 \mathrm{~mm}-0.25 \%$ versus $0 \mathrm{~mm}-0.5 \%$ with $p<0.001$. Comparing the effect of thermocycling on impact strength for each group showed a significant

Table 2 One-way ANOVA analysis of tested properties before and after thermocycling

\begin{tabular}{|c|c|c|c|c|c|c|c|}
\hline Thermocycling & Property & Group & Sum of squares & df & Mean square & F-Value & Sig. \\
\hline \multirow[t]{9}{*}{ Before } & \multirow[t]{3}{*}{ Flexural strength } & Between groups & 533.688 & 4 & 133.422 & 114.673 & $0.000^{\mathrm{a}}$ \\
\hline & & Within groups & 23.270 & 20 & 1.163 & & \\
\hline & & Total & 556.958 & 24 & & & \\
\hline & \multirow[t]{3}{*}{ Elastic modulus } & Between groups & 1312503.170 & 4 & 328125.792 & 8.098 & $0.000^{\mathrm{a}}$ \\
\hline & & Within groups & 810387.427 & 20 & 40519.371 & & \\
\hline & & Total & 2122890.597 & 24 & & & \\
\hline & \multirow[t]{3}{*}{ Impact strength } & Between groups & 10.844 & 4 & 2.711 & 19.222 & $0.000^{a}$ \\
\hline & & Within groups & 2.821 & 20 & 0.141 & & \\
\hline & & Total & 13.665 & 24 & & & \\
\hline \multirow[t]{9}{*}{ After } & \multirow[t]{3}{*}{ Flexural strength } & Between groups & 270.561 & 4 & 67.640 & 39.464 & $0.000^{\mathrm{a}}$ \\
\hline & & Within groups & 34.279 & 20 & 1.714 & & \\
\hline & & Total & 304.841 & 24 & & & \\
\hline & \multirow[t]{3}{*}{ Elastic modulus } & Between groups & 6170232.621 & 4 & 1542558.155 & 52.281 & $0.000^{\mathrm{a}}$ \\
\hline & & Within groups & 590099.477 & 20 & 29504.974 & & \\
\hline & & Total & 6760332.098 & 24 & & & \\
\hline & \multirow[t]{3}{*}{ Impact strength } & Between groups & 2.016 & 4 & 0.504 & 7.020 & $0.001^{\mathrm{a}}$ \\
\hline & & Within groups & 1.436 & 20 & 0.072 & & \\
\hline & & Total & 3.452 & 24 & & & \\
\hline
\end{tabular}

Abbreviation: ANOVA, analysis of variance.

${ }^{\text {a }}$ Statistically significant at 0.05 level of significance. 


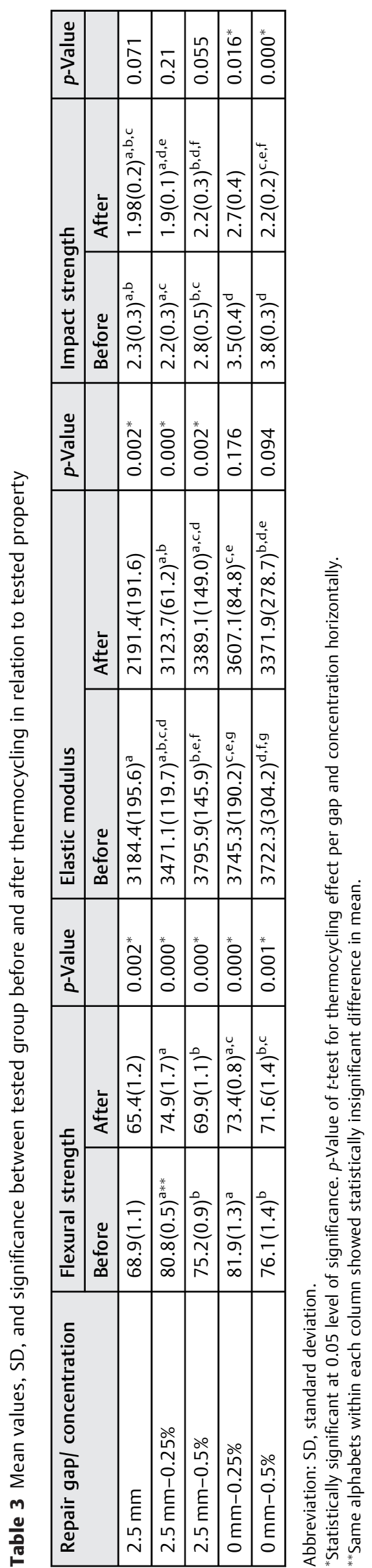

reduction only in $0 \mathrm{~mm}-0.25 \%(p=0.016)$ and $0 \mathrm{~mm}-0.5 \%$ $(p=0.000)$ (-Table 3$)$.

Combined effect of thermocycling and repair gap with ND concentration was analyzed through two-way ANOVA and test was run separately for each property (-Table 4). It was found that combined effect of thermocycling and repair gap had significant effect on each tested property. As shown in -Table 5, there were variations in nature of failure of $2.5 \mathrm{~mm}$ unmodified repair gap showing mostly adhesive, followed by cohesive failure. While in ND repair groups, the dominant type of failure was adhesive, in addition to the absence of cohesive fracture and increase of mixed fracture especially with $0 \mathrm{~mm}$ repair gap. According to chisquared test, no significant difference was found in fracture type before and after thermocycling.

The representative micrographs were displayed at medium magnification of $x 1000$ to show the important surface features of both 0 - and $2.5 \mathrm{~mm}$ specimens after going through flexural strength tests (-Figs. 4 and 5). - Fig. 4A showed a smooth surface represents a brittle fracture type for control specimen, while ND addition specimens $(0.25 \%$ and $0.5 \% \mathrm{ND}$ ) showed different topographical features, the surface is rough with thicker lamellae (-Figs. 4B, 4C, and 5). With $0.25 \% \mathrm{ND}$ addition, irregular FS with multiple sharp step lamellae indicated ductile fracture mode, in addition to the absence of clusters which indicates well distribution of nanoparticles within PMMA resin matrix (-Figs. 4B and $\mathbf{5 A}$ ). With increasing concentration of ND addition $(0.5 \% \mathrm{ND})$, the FS showed same irregular and sharp lamella but with some small cluster formation of ND particles (-Figs. 4C and 5B).

\section{Discussion}

One of the improvements in denture repair is the repair resin reinforcement with nanoparticles. Previous studies have suggested ND addition to heat polymerized PMMA denture base resins. ${ }^{18,19,22}$ However, no previous studies investigated its addition to repair resin along with different repair gap size. Therefore, this in vitro study aimed to assess the influence of ND addition combined with repair gap modifications on the flexural strength, elastic modulus, and impact strength of repaired denture base. The first and second null hypotheses of the present study were rejected since the size of repair gap and the addition of ND affected the repair strength and significantly improved the flexural strength, elastic modulus, and impact strength.

The continuous masticatory forces cause deformation of denture base material; therefore, high flexural strength is required to decrease the probability of denture fracture. ${ }^{23}$ Among the factors that could affect the repair strength is the repair material reinforcement and/or surface design. ${ }^{2}$ Depending on the results of the present study, the flexural strength increased in comparison to control group. This increase could be attributed to the well distribution of fine ND within resin matrix. ${ }^{22}$ Furthermore, treated NDs have several reactive groups such as $-\mathrm{COOH}$ and $-\mathrm{OH}$ that improve the bond between NDs and resin matrix. Heat treatment of 
Table 4 Two-way ANOVA for flexural strength, impact strength, and elastic modulus

\begin{tabular}{|c|c|c|c|c|c|c|}
\hline Property & Source & Type III sum of squares & df & Mean square & F-Value & p-Value \\
\hline \multirow[t]{5}{*}{ Flexural strength } & Gap concentration & 769.685 & 4 & 192.421 & 133.744 & $0.000^{\mathrm{a}}$ \\
\hline & Thermocycling & 382.317 & 1 & 382.317 & 265.732 & $0.000^{\mathrm{a}}$ \\
\hline & Gap concentration ${ }^{\mathrm{a}}$ thermocycling & 34.564 & 4 & 8.641 & 6.006 & $0.001^{\mathrm{a}}$ \\
\hline & Error & 57.549 & 40 & 1.439 & & \\
\hline & Total & 273802.326 & 50 & & & \\
\hline \multirow[t]{5}{*}{ Elastic modulus } & Gap concentration & 6446992.927 & 4 & 1611748.232 & 46.034 & $0.000^{\mathrm{a}}$ \\
\hline & Thermocycling & 2499946.385 & 1 & 2499946.385 & 71.402 & $0.000^{\mathrm{a}}$ \\
\hline & Gap concentration ${ }^{a}$ thermocycling & 1035742.863 & 4 & 258935.716 & 7.396 & $0.000^{\mathrm{a}}$ \\
\hline & Error & 1400486.905 & 40 & 35012.173 & & \\
\hline & Total & 575939242.042 & 50 & & & \\
\hline \multirow[t]{5}{*}{ Impact strength } & Gap concentration & 9.410 & 4 & 2.352 & 22.107 & $0.000^{\mathrm{a}}$ \\
\hline & Thermocycling & 6.351 & 1 & 6.351 & 59.683 & $0.000^{\mathrm{a}}$ \\
\hline & Gap concentration ${ }^{\mathrm{a}}$ thermocycling & 3.450 & 4 & .863 & 8.105 & $0.000^{\mathrm{a}}$ \\
\hline & Error & 4.257 & 40 & .106 & & \\
\hline & Total & 348.388 & 50 & & & \\
\hline
\end{tabular}

Abbreviation: ANOVA, analysis of variance.

${ }^{\text {aS }}$ tatistically significant at 0.05 level of significance.

Table 5 Nature of failure of flexural strength specimens

\begin{tabular}{|c|c|c|c|c|c|}
\hline \multirow[t]{2}{*}{ Groups } & \multirow[t]{2}{*}{ Thermocycling } & \multicolumn{3}{|c|}{ Nature of failure } & \multirow[t]{2}{*}{$p$-Value } \\
\hline & & Adhesive & Cohesive & Mixed & \\
\hline \multirow[t]{2}{*}{$2.5 \mathrm{~mm}$} & Before & 6 & 3 & 1 & 0.89 \\
\hline & After & 5 & 4 & 1 & \\
\hline \multirow[t]{2}{*}{$2.5 \mathrm{~mm}-25 \% \mathrm{ND}$} & Before & 8 & - & 2 & 1.00 \\
\hline & After & 9 & - & 1 & \\
\hline \multirow[t]{2}{*}{$2.5 \mathrm{~mm}-0.5 \% \mathrm{ND}$} & Before & 9 & - & 1 & 1.00 \\
\hline & After & 10 & - & - & \\
\hline \multirow[t]{2}{*}{$0 \mathrm{~mm}-0.25 \% \mathrm{ND}$} & Before & 7 & - & 3 & 1.00 \\
\hline & After & 6 & - & 4 & \\
\hline \multirow[t]{2}{*}{$0 \mathrm{~mm}-0.5 \% \mathrm{ND}$} & Before & 7 & - & 3 & 1.00 \\
\hline & After & 7 & - & 3 & \\
\hline
\end{tabular}

Note: All p-values are statistically insignificant.

NDs was done to increase the interaction between ND and PMMA resin matrix (carbonyl groups) ${ }^{20}$ and decrease particles agglomeration. ${ }^{18}$

According to the finding of this study, the flexural strength decreased as ND concentration increased (0.5\%). As the concentration increased above saturation limit, ND agglomerated forming clusters that affect the flexural strength of reinforced resin. ${ }^{18} \mathrm{Al}$-Harbi et $\mathrm{al}^{18}$ added $0.5,1$, and $1.5 \mathrm{wt} \%$ ND and reported an increased strength with $0.5 \%$ filler, while declined as ND concentration increased. Also, a previous study, ${ }^{22}$ has found a significant increase in strength with the incorporation of $0.5 \mathrm{wt} \% \mathrm{ND}$. Accordingly, the recommended ND addition to denture base material in low concentrations is in agreement with the finding of the present study. Low ND showed higher flexural strength before and after thermocycling. This may be due to the saturation level at $0.25 \%$ and after that clusters were formed with increased concentrations up to $0.5 \%$.

Repair gap decreasing up to $0 \mathrm{~mm}$ with 45 degrees beveling was suggested in previous study and observed that the repair strength improved with decrease in the repair gap and recommended $0 \mathrm{~mm}, 0.5 \mathrm{~mm}$, or $1.0 \mathrm{~mm}$ with beveled repair surface design. ${ }^{5}$ Therefore, $0 \mathrm{~mm}$ repair gap was selected for comparison in the present study. Based on the results of present study, although $0 \mathrm{~mm}$ substantially improved the flexural strength as compared with control, the repair gap did not show significant differences per respective concentrations in disagreement with a prior study that found 

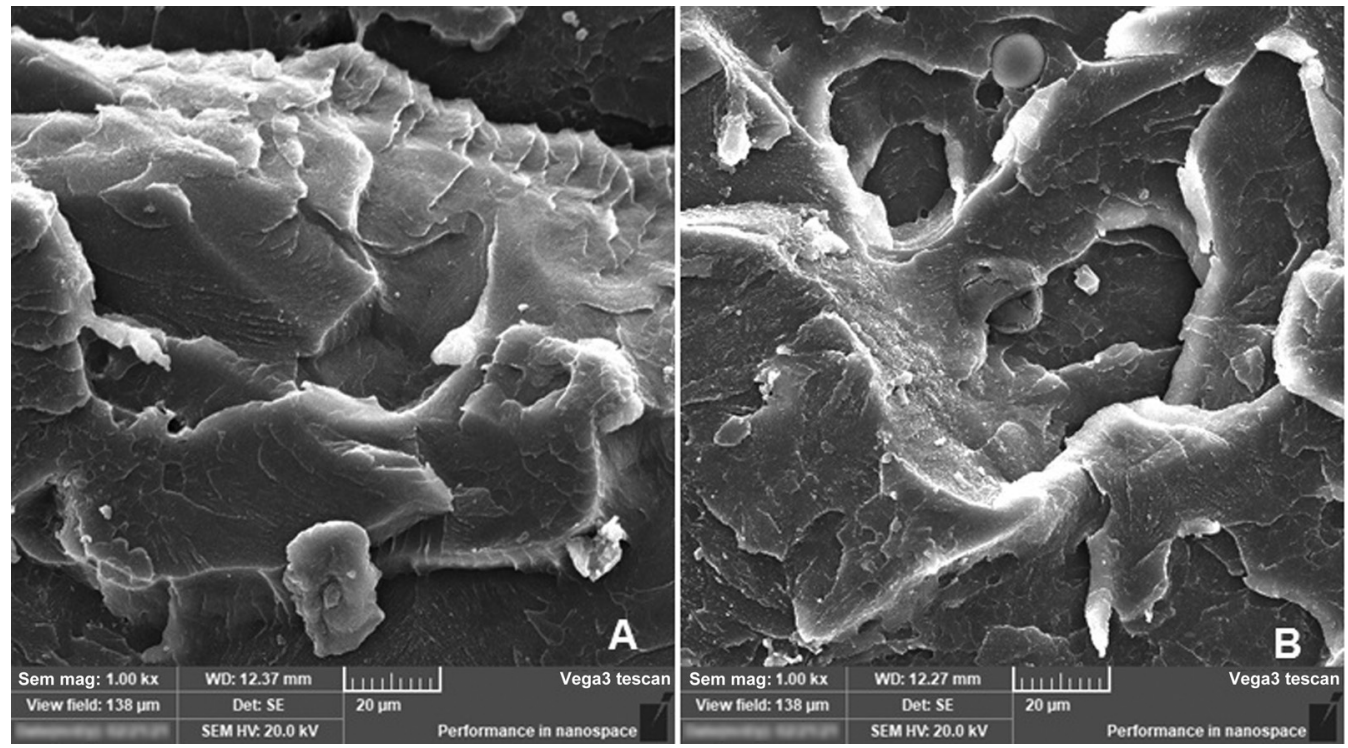

Fig. 5 Representative scanning electron microscopy images for fracture surface of flexural strength test specimens 0 mm groups after thermocycling. (A) $0 \mathrm{~mm}-0.25 \% \mathrm{ND}$ ), (B) $0 \mathrm{~mm}-0.5 \% \mathrm{ND}$

remarkable improvement of flexural strength at $0 \mathrm{~mm}$ repair gap. ${ }^{5}$ The differences in results may be related to the presence of ND as reinforcement for repair resin that may have changed the behavior of material during failure.

In concern thermal stress effect, the flexural strength decreased significantly after thermocycling and there was a significant decrease per respective concentrations and repair gap. A previous study showed similar results of 23 substantial reduction in flexural strength following thermal stressing. This effect may be attributed to water sorption, that results in. ${ }^{24,25}$ water molecules occupying inter-polymeric gap and forcing the polymer chains apart. ${ }^{26,27}$ In addition to the plasticizing effect of absorbed water that allows the chains to slide easily under load, affecting the mechanical properties of resin material. ${ }^{28,29}$ Intraorally, moisture and thermal fluctuation accelerate water absorption. ${ }^{25}$ Water absorption rate is affected by temperature ${ }^{28}$ therefore, thermal stress may enhance water entrance into the polymer mass decreasing the polymer's strength after thermal cycling specially at repair/resin interface. ${ }^{24,29}$

In the nonreinforced group, adhesive failure was common before and after thermocycling, while ND-reinforced groups showed more adhesive and disappearance of cohesive fractures exhibited strong repair material and weakness at repair/resin interface. The nature of failure was closely the same after thermocycling per respective concentrations and repair gap, where the mixed failure was appeared with $0 \mathrm{~mm}$ repair gap. This finding proves the influence of thermal stress on the repair bond strength at the resin/repair interface and thin edge of $0 \mathrm{~mm}$ gap displayed mixed failure. In agreement with previous study, ${ }^{28}$ reported more adhesive failures of repaired denture base after thermocycling.

Elastic modulus affects material rigidity, as it increases in the value, the elastic deformation decreases, thus the material would be more rigid. ${ }^{31} \mathrm{~A}$ denture base material with high elastic modulus can resist permanent deformation c caused by constant stress or strain during mastication, ${ }^{31,32}$ The results showed increase of, the elastic modulus with $0.5 \%$ NDs at $2.5 \mathrm{~mm}$ and $0.25 \%$ and $0.5 \% \mathrm{NDs}$ at $0 \mathrm{~mm}$ compared to control group and above the minimum recommended value (2000 MPa) by ADA specifications. ${ }^{33}$ The probable cause for the increased elastic modulus could be explained based on the homogenous distribution and micro-size distance between NDs minimizing the polymer chain immobilization effect. $^{31,32}$ Another advantage of decreasing repair gap is reducing the amount of autopolymerized repair resin and subsequently its drawbacks. ${ }^{5}$ When comparing elastic modulus of $0 \mathrm{~mm}$ with $2.5 \mathrm{~mm}$ after thermocycling, $2.5 \mathrm{~mm}$ groups significantly decreased with no effect on $0 \mathrm{~mm}$ group. This may be related to increased amount of repair material and effect of water sorption and thermal stress on the increase amount of repair resin in comparison to $0 \mathrm{~mm}$ repair gap. ${ }^{5}$

The main cause of denture fracture is accidental drop that may occur during denture cleaning, coughing, sneezing, or sudden strokes to the denture. ${ }^{34}$ Accordingly, adequate impact strength is important for denture base resin to resist denture fracture and improve its durability. ${ }^{18}$ Charpy's impact test was chosen for this study in which v-shaped notches were made in the specimens resembling denture frenal notch to act as stress concentration area. ${ }^{10}$ This was confirmed by the nature of failure of impact specimens where all specimens displayed cohesive fracture type at the v-notch.

The results revealed that the addition of ND did not alter the impact strength in $2.5 \mathrm{~mm}$ groups. This finding was coincidence with previous study which found that $0.5 \% \mathrm{ND}$ did not affect the impact strength off denture base resin. ${ }^{5}$ In contrast, $0 \mathrm{~mm}$ groups increased the impact strength of repaired specimens. As the concentration was same for both gaps, this effect may be due to the decreased amount of repair resin and this was proven by thermal stress effects 
where $0 \mathrm{~mm}$ groups showed increased impact strength even after thermocycling. Comparing thermocycling effect per respective gap and concentrations, the impact strength was decreased and this may be attributed to the aforementioned effect of thermal stress and water sorption on PMMA resin material.

From the clinical point of view, repair resin could be modified with low ND concentrations. This addition significantly improved the repair strength combined with $0 \mathrm{~mm}$ repair gap that considered a positive effect with ND addition. However, the results of this study could be interpreted with cautions before clinical applicability due to the limitation of this study. These limitations included using one brand of denture base resin and repair resin, and specimens were not simulating denture configurations. Moreover, in vitro study lacks oral conditions such as saliva and masticatory forces. Therefore, further studies on different repair resin material with low ND concentrations in conditions simulating oral environments are required.

\section{Conclusions}

The following conclusions can be drawn:

1. Incorporating $0.25 \%$ and $0.5 \%$ ND into autopolymerized repair resin substantially improved the flexural strength, elastic modulus, and impact strength of repaired denture base resin.

2. $0 \mathrm{~mm}$ repair gap had no influence on flexural strength while elastic modulus and impact strength were significantly improved.

3. Thermocycling adversely affected the repair strength with ND addition combined with repair gap modifications.

Funding

None.

\section{Conflict of Interest}

None declared.

\section{Acknowledgments}

The authors would like to thank Mr. Roberto Caravana for his assistance with the mechanical testing.

\section{References}

1 Praveen B, Babaji HV, Prasanna BG, Rajalbandi SK, Shreeharsha TV, Prashant GM. Comparison of impact strength and fracture morphology of different heat cure denture acrylic resins: an in vitro study. J Int Oral Health 2014;6(05):12-16

2 Seó RS, Neppelenbroek KH, Filho JN. Factors affecting the strength of denture repairs. J Prosthodont 2007;16(04):302-310

3 Polyzois GL, Tarantili PA, Frangou MJ, Andreopoulos AG. Fracture force, deflection at fracture, and toughness of repaired denture resin subjected to microwave polymerization or reinforced with wire or glass fiber. J Prosthet Dent 2001;86(06):613-619

4 Bural C, Bayraktar G, Aydin I, Yusufoğlu I, Uyumaz N, Hanzade M. Flexural properties of repaired heat-polymerising acrylic resin after wetting with monomer and acetone. Gerodontology 2010; 27(03):217-223
5 Gad MM, Rahoma A, Abualsaud R, Al-Thobity AM, Fouda SM. Effect of repair gap width on the strength of denture repair: an in vitro comparative study. J Prosthodont 2019;28(06):684-691

6 Beyli MS, von Fraunhofer JA. Repair of fractured acrylic resin. J Prosthet Dent 1980;44(05):497-503

7 Shanoj RP, Razak PA, Kumar KN, Francis J, Ashok K, Sameer KK. Comparative evaluation of the strength of denture base resin repaired with glass fiber-reinforced acrylic resin: an in vitro study. J Contemp Dent Pract 2018;19(07):792-798

8 Leong A, Grant AA. The transverse strength of repairs in polymethyl methacrylate. Aust Dent J 1971;16(04):232-234

9 Hanna EA, Shah FK, Gebreel AA. Effect of joint surface contours on the transverse and impact strength of denture base resin repaired by various methods: an in vitro study. J Am Sci 2010;6(09): 115-125

10 Gad MM, Rahoma A, Al-Thobity AM, ArRejaie AS. Influence of incorporation of $\mathrm{ZrO}_{2}$ nanoparticles on the repair strength of polymethyl methacrylate denture bases. Int J Nanomedicine 2016;11(27):5633-5643

11 Gad M, ArRejaie AS, Abdel-Halim MS, Rahoma A. The reinforcement effect of nano-zirconia on the transverse strength of repaired acrylic denture base. Int J Dent 2016;2016:7094056

12 Gad MM, Fouda SM, Al-Harbi FA, Näpänkangas R, Raustia A. PMMA denture base material enhancement: a review of fiber, filler, and nanofiller addition. Int J Nanomedicine 2017;12(12): 3801-3812

13 Vallittu PK. A review of methods used to reinforce polymethyl methacrylate resin. J Prosthodont 1995;4(03):183-187

14 Gad MMA, Abualsaud R, Al-Thobity AM, et al. Effect of $\mathrm{SiO}_{2}$ nanoparticles addition on the flexural strength of repaired acrylic denture base. Eur J Dent 2020;14(01):19-23

15 Tamore SH, Jyothi KS, Muttagi S, Gaikwad AM. Flexural strength of surface-treated heat-polymerized acrylic resin after repair with aluminum oxide-reinforced autopolymerizing acrylic resin. Contemp Clin Dent 2018;9(02, Suppl 2):S347-S353

$16 \mathrm{Al}-$ Mahdy YF, Eltayeb HE. The Effect of Nano- $\mathrm{ZrO}_{2}$ and nano- $\mathrm{Al}_{2} \mathrm{O}_{3}$ reinforcement on flexural and impact strength of repaired acrylic denture base. ADJ-for Girls 2018;5(01):89-100

17 Karbushev VV, Konstantinov II, Parsamyan IL, et al. Preparation of polymer-nanodiamond composites with improved properties. Adv Mat Res 2009;59:275-278

18 Al-Harbi FA, Abdel-Halim MS, Gad MM, et al. Effect of nanodiamond addition on flexural strength, impact strength, and surface roughness of PMMA denture base. J Prosthodont 2019; 28(01):e417-e425

19 Fouda SM, Gad MM, Ellakany P, et al. The effect of nanodiamonds on candida albicans adhesion and surface characteristics of PMMA denture base material - an in vitro study. J Appl Oral Sci 2019;27(27):e20180779

20 Protopapa P, Kontonasaki E, Bikiaris D, Paraskevopoulos KM, Koidis P. Reinforcement of a PMMA resin for fixed interim prostheses with nanodiamonds. Dent Mater J 2011;30(02): 222-231

21 ISO 1567. Dentistry - Denture Base Polymer. Geneva: International Organization for Standardization; Geneva, Switzerland. 1999:1-27

22 Mangal U, Kim JY, Seo JY, Kwon JS, Choi SH. Novel poly(methyl methacrylate) containing nanodiamond to improve the mechanical properties and fungal resistance. Materials (Basel) 2019;12 (20):3438

23 Barbosa DB, de Souza RF, Pero AC, Marra J, Compagnoni MA. Flexural strength of acrylic resins polymerized by different cycles. J Appl Oral Sci 2007;15(05):424-428

24 Gad MM, Rahoma A, Abualsaud R, et al. Impact of different surface treatments and repair material reinforcement on the flexural strength of repaired PMMA denture base material. Dent Mater J 2020;39(03):471-482 
25 Wady AF, Machado AL, Vergani CE, Pavarina AC, Giampaolo ET. Impact strength of denture base and reline acrylic resins subjected to long-term water immersion. Braz Dent J 2011;22(01):56-61

26 Barclay CW, Spence D, Laird WR. Intra-oral temperatures during function. J Oral Rehabil 2005;32(12):886-894

27 Silva CdeS, Machado AL, Chaves CdeA, Pavarina AC, Vergani CE. Effect of thermal cycling on denture base and autopolymerizing reline resins. J Appl Oral Sci 2013;21(03):219-224

28 Lin CT, Lee SY, Tsai TY, Dong DR, Shih YH. Degradation of repaired denture base materials in simulated oral fluid. J Oral Rehabil 2000;27(03):190-198

29 Minami H, Suzuki S, Minesaki Y, Kurashige H, Tanaka T. In vitro evaluation of the influence of repairing condition of denture base resin on the bonding of autopolymerizing resins. J Prosthet Dent 2004;91(02):164-170
30 Machado AL, Puckett AD, Breeding LC, Wady AF, Vergani CE. Effect of thermocycling on the flexural and impact strength of urethanebased and high-impact denture base resins. Gerodontology 2012; 29(02):e318-e323

31 McCabe JF, Walls AG. Applied Dental Materials. 8th edition Oxford: Blackwell Science; 1998:97

32 Ajaj-Alkordy NM, Alsaadi MH. Elastic modulus and flexural strength comparisons of high-impact and traditional denture base acrylic resins. Saudi Dent J 2014;26(01):15-18

33 American Dental Association. Revised American Dental Association specification no. 12 for denture base polymers. J Am Dent Assoc 1975;90(02):451-458

34 Balos S, Puskar T, Potran M, et al. Modulus, strength and cytotoxicity of PMMA-silica nanocomposites. Coatings 2020;10:583 